\title{
XLIV. The secular annealing of cold hard steel
}

\section{Carl Barus}

To cite this article: Carl Barus (1888) XLIV. The secular annealing of cold hard steel, Philosophical Magazine Series 5, 26:162, 397-403, DOI: 10.1080/14786448808628286

To link to this article: http://dx.doi.org/10.1080/14786448808628286

曲 Published online: 29 Apr 2009.

Submit your article to this journal 준

Џ Article views: 2

Q View related articles $\sqsubset$ 
LONDON, EDINBURGH, AND DUBLIN

\title{
PHILOSOPHICAL MAGAZINE
}

\author{
AND \\ JOURNAL OF SCIENCE.
}

[FIFTH SERIES.]

NOVEMBER 1888.

XLIV. The Secular Annealing of Cold Hard Steel. By Carl Barus*.

TNASMUCH as the method I used for testing Maxwell's 1 theory of the viscosity of solids contains a proof of that theory a fortiori, I did not distinguish in my last paper $\dagger$ between a break-up of configurations of molecular wholes and the more intensified break-up in which the integrity of the molecule itself is invaded. The experimental distinction is not always easy. If, for instance, I dissolve certain solids (pitch, say, in turpentine) I may produce a continuous series of viscous fluids ; but the molecular mechanism by which this is brought about cannot in the present state of our knowledge of solution be said to be known. I may cite another striking exampleebonite, which above $100^{\circ}$ loses viscosity at an exceedingly rapid rate by mere beating ; but, again, the molecular change which produces the viscous effect is obscure. And so generally in less remarkable experiments $\ddagger$. In the case of metals, it appears that those elements whose molecules are least stable and possibly monatomic $\S(\mathrm{K}, \mathrm{Na}, \& \mathrm{c}$.) are of a soapy consistency, so that here viscosity ("Nachwirkung") and permanent set can hardly be distinguished. In general it appears that metallic permanent set is physical manifestation of looseness of molecular structure. If, as in the case of annealing glass-hard steel, the rigid arch (say) of molecular wholes breaks up because one or more of the molecules, the stones of

- Communicated by the Author.

+ This Magazine, August 1888.

f C'f. Lothar Meyer (Die modernen Theorien der Chemie, Breslau, 1884, chapter viii.), on solid molecular structure.

$\S$ Ibid. chapter. xvi. $\$ 308$, \&c.

Phil. Mag. S. 5. Vol. 26. No. 162. Nov. $1888 . \quad 2 \mathrm{E}$ 
that arch, disintegrate, and if the decomposition be of a kind that the débris may be chemically recognized, then, by coordinating the viscous and the chemical observations, I obtain a fairly good notion of the molecular mechanism which has produced the viscous effect. This is the method I applied to prove Maxwell's theory. But partial disintegration or reconstruction of molecules may easily be conceived to occur in such a way as to escape detection altogether, or at least to escape detection as much as does a break-up of configurations of molecular wholes. It may, I think, be reasonably supposed that the solid molecule is of the form $\mathrm{M}_{n}$, in. which $n$ is variable; and any given value of $n$ will occur less frequently according as it is proportionately greater or less than the mean or typical value of $n$ for the solid. The effect of strain, of change of strain, or even of long continued secular subsidence, is merely to vary the distribution of molecules $\mathrm{M}_{n}$, so that the general properties of any observably finite part of the solid do not change*.

I will adduce other points of view in succeeding papers; but the suggestions stated are sufficient, I think, to show the importance of discerning whether the cause of viscous deformation in tempered steel is the type of viscous deformation in general; or whether, in using the phenomena of annealing steel to test Maxwell's theory, I have merely interpreted the exception to prove the rule. The result of such an investigation, besides throwing light on the structure of solid matter, must ultimately lead to inferences bearing directly on the questions of fusion, solution, and volatilization.

This inquiry being essentially a comparison of detail, will consume much time before it can be brought to an issue; and as the individual parts of my work have led to results which are of interest + apart from the purposes to which I hope ultimately to apply them, it is perhaps best to commu-

* In other words, it is here supposed that the assumption of solid state has not thoroughly eliminated either the liquid or even the gaseous molecule; and that it has, on the other hand, produced molecules of an ultra-solid complexity. Here I touch the keynote of certain difficulties in my mind against conceiving the solid molecule as a uniformly distinct whole, capable of rotation (Kohlrausch viscosity), or capable of translation from strained to isotropic configuration (Maxwell viscosity). I look upon it as a more cumbersome thing, which may under favourable conditions even lose its identity, and which, when undergoing the motions stated, comes into serious conflict with contiguous molecules. Such a view, even if it be mere surmise (excepting the case of hard steel discussed) is a suggestive working hypothesis; for it seems broad enough to enable me to circumscribe the true phenomenon by clipping the postulate. This is the general endeavour of wy present work.

$t$ It is well known that experiments on the secular changes of metals are being made at Glasgow by Mr. Bottomley. Cf. Brit. Assoc. Report, p. 537 (1888). 
nicate the data separately. The following results on the secular annealing of cold glass-hard steel essentially sustain the inferences of my last paper. They were omitted because of the space occupied by the discussions there given. The rods to which the data refer are of Stubs's best steel, tempered in a special apparatus*, by aid of which the wire heated to redness electrically is suddenly whipped into water. Freshly quenched samples of wire showed specific resistances $\left(0^{\circ} \mathrm{C}\right.$.) as high as $s=48$. All the rods were tested for longitudinal uniformity of temper by stepping off, as it were, the resistance of lengths of 2 centim. each, for each of the consecutive 3 centim. of wire. The total length being about 25 centim., eight measurements were thus made. A device utilizing Matthiessen and Hoskin's method, and provided with a suitable rider, enabled me to do this with reasonable accuracy. Table I. contains the results as obtained with three batches of wire, of the diameters $2 \rho=\cdot 081$ centim., $\cdot 044$ centim., and - 127 centim. respectively. The approximate resistance (microhms) of the 2 centim. of length is designated by $r$.

TABLE I.-Iongitudinal Uniformity of Temper of the Steel Rods. Variation from Mean, in terms of the Electrical Interval Hard-soft.

\begin{tabular}{|c|c|c|c|c|c|c|c|c|c|}
\hline $\begin{array}{c}\text { No. } 1 . \\
r=18500 .\end{array}$ & $\begin{array}{l}\text { No. } 2 . \\
18500 .\end{array}$ & $\begin{array}{l}\text { No. } 3 . \\
17700\end{array}$ & $\begin{array}{l}\text { No. } 4 . \\
17600 .\end{array}$ & $\begin{array}{l}\text { No. } 5 . \\
17700 .\end{array}$ & $\begin{array}{l}\text { No. } 6 . \\
18500 .\end{array}$ & $\begin{array}{l}\text { No. } 7 . \\
18400 .\end{array}$ & $\begin{array}{l}\text { No. } 8 . \\
18500 .\end{array}$ & $\begin{array}{l}\text { No. } 9 . \\
17400 .\end{array}$ & $\begin{array}{l}\text { No. } 10 . \\
17900 .\end{array}$ \\
\hline $\begin{array}{r}002 \\
4 \\
-\quad 1 \\
-\quad 6 \\
-\quad 4 \\
-\quad 4\end{array}$ & $\begin{array}{r}002 \\
-\quad 2 \\
-\quad 2 \\
-\quad 2 \\
-\quad 2 \\
-\quad 6 \\
-\quad 2 \\
\quad 10\end{array}$ & $\begin{array}{r}000 \\
0 \\
5 \\
5 \\
5 \\
-\quad 13 \\
-\quad 0 \\
-\quad 4\end{array}$ & $\begin{array}{r}003 \\
-\quad 2 \\
-\quad 2 \\
-\quad 7 \\
-\quad 2 \\
-\quad 6 \\
-\quad 2 \\
-\quad 3\end{array}$ & $\begin{array}{r}010 \\
10 \\
-\quad 7 \\
-\quad 2 \\
-\quad 7 \\
-\quad 11 \\
-\quad 2\end{array}$ & $\begin{array}{r}005 \\
-\quad 3 \\
-\quad 7 \\
5 \\
-\quad 1 \\
-\quad 7 \\
9\end{array}$ & $\begin{array}{r}-004 \\
1 \\
1 \\
7 \\
-\quad 5 \\
-\quad 8 \\
-\quad 5\end{array} \mid$ & $\begin{array}{r}009 \\
-\quad 11 \\
-\quad 11 \\
-\quad 5 \\
-\quad 3 \\
5 \\
5 \\
1\end{array}$ & $\begin{array}{r}032 \\
18 \\
11 \\
-\quad 46 \\
-\quad 64 \\
-\quad 16 \\
23 \\
41\end{array}$ & $\begin{array}{r}006 \\
-\quad 6 \\
-\quad 2 \\
-\quad 2 \\
-\quad 2 \\
-\quad 6 \\
-\quad 10 \\
-\quad 6\end{array}$ \\
\hline $\begin{array}{c}\text { No. } 11 . \\
r=61200 .\end{array}$ & 60600 & & 60200. & No. 15. & $\begin{array}{c}\text { No. } 16 . \\
r=6800 .\end{array}$ & 6760. & No. 18 & 7290. & 6850. \\
\hline $\begin{array}{r}007 \\
-\quad 2 \\
-\quad 7 \\
-\quad 10 \\
1 \\
1 \\
1 \\
10\end{array}$ & {$\left[\begin{array}{rr}- & -007 \\
- & 1 \\
- & 4 \\
- & 7 \\
- & 4 \\
- & 4 \\
13\end{array} \mid\right.$} & $\begin{array}{r}-003 \\
-\quad 3 \\
-\quad 3 \\
-\quad 10 \\
-\quad 5 \\
-\quad 3 \\
8 \\
8\end{array}$ & $\begin{array}{r}023 \\
-\quad 1 \\
-\quad 1 \\
-\quad 7 \\
-\quad 4 \\
-\quad 4 \\
-\quad 4 \\
-\quad 4\end{array}$ & {$\left[\begin{array}{rr}0 & 016 \\
- & 1 \\
- & 3 \\
- & 9 \\
& 2 \\
- & 12 \\
- & 1 \\
& 8\end{array} \mid\right.$} & $\begin{array}{r}-006 \\
-\quad 2 \\
-\quad 3 \\
-\quad 2 \\
-\quad 2 \\
-\quad 2 \\
\quad 3 \\
7\end{array}$ & $\begin{array}{r}-001 \\
1 \\
-\quad 3 \\
-\quad 3 \\
-\quad 3 \\
-\quad 3 \\
\quad 1\end{array}$ & {$\left[\begin{array}{r}-009 \\
7 \\
15 \\
3 \\
-\quad 1 \\
-\quad 11 \\
-\quad 20\end{array} \mid\right.$} & $\begin{array}{r}001 \\
1 \\
10 \\
10 \\
14 \\
-\quad 11 \\
-\quad 11 \\
-11\end{array}$ & $\begin{array}{r}-013 \\
-\quad 26 \\
4 \\
17 \\
13 \\
13 \\
-\quad 13 \\
4\end{array}$ \\
\hline
\end{tabular}

* Bulletin U. S. Geological Survey, No. 14, p. 29 (1885). My present apparatus is horizontal in form, and enables me to quench the wires from any degree of red heat in water or other liquid at any desirable temper'ature. 
With the exception of No. 9, the variations are, as a rule, well within one per cent. of the electrical value of the interval hard-soft. Where the resistance is larger or smaller than the mean value, it is possible that the parts were accidentally splashed by the water immediately before quenching, or quenched at a different degree of red heat. But inasmuch as the series of measurements for each rod takes some time, and as the effective resistances are necessarily small, I believe that the rods are even more homogeneous than Table I. indicates; for the errors introduced by variations of temperature, by the difficulty of clamping the thin, very brittle rods (soldering would change the temper enormonsly), and by other inconveniences of manipulation, are by no means negligible. Hence the degree of homogeneity found may be considered quite satisfactory.

In Table II. I give the mass $m$, length $l$, and density at $0^{\circ} \mathrm{C} ., \Delta_{0}$, of some of the rods. The latter datum is essential for the determination of the sections. I shall also use it in the future in determining the secular volume-changes of these wires. Rods Nos. 11 to 15 are too thin for direct measurement. Hence a mean value of $\Delta_{0}$ was here assumed. I may add that in the soft state the density of these rods is about $\Delta_{0}=7 \cdot 80$.

Table II.-Mass Constants of the Glass-hard Steel Rods, June, 1885.

\begin{tabular}{|c|c|c|c|c|c|c|c|}
\hline No. & $m$. & $l$. & $\Delta_{0}$ & No. & $m$ & l. & $\Delta_{0}$ \\
\hline & $g$. & centin. & $\mathrm{g} / \mathrm{cm}^{8}$. & & g. & centim. & $\mathrm{g} / \mathrm{cm} .^{3}$ \\
\hline 1 & .9910 & 24.95 & $7 \cdot 710$ & 11 & $\cdot 3257$ & $27 \cdot 94$ & \\
\hline 2 & .9544 & 24.02 & $7 \cdot 689$ & 12 & -3322 & $28 \cdot 30$ & \\
\hline 3 & .9970 & $25 \cdot 25$ & $7 \cdot 703$ & 13 & -3170 & $27 \cdot 20$ & \\
\hline 4 & $1 \cdot 0483$ & $26 \cdot 30$ & $7 \cdot 705$ & 14 & .2888 & 24.35 & \\
\hline $\overrightarrow{5}$ & 1.0079 & $25 \cdot 46$ & $7 \cdot 703$ & 15 & $\cdot 3004$ & 2607 & \\
\hline 6 & 1.0243 & $25 \cdot 80$ & $7 \cdot 687$ & 16 & $2 \cdot 4713$ & $25 \cdot 63$ & $7 \cdot 676$ \\
\hline 7 & 1.0089 & $25 \cdot 47$ & $7 \cdot 670$ & 17 & $2 \cdot 4857$ & $25 \cdot 70$ & $7 \cdot 671$ \\
\hline 8 & 1.0074 & 25.50 & $7 \cdot 682$ & 18 & $2 \cdot 1043$ & $22 \cdot 50$ & $7 \cdot 544$ \\
\hline 9 & 1.066 & $26 \cdot 6$ & $7 \cdot 726$ & 19 & 25327 & 26.06 & $7 \cdot 685$ \\
\hline 10 & 1.0293 & 25.58 & $7 \cdot 719$ & 20 & $2 \cdot 3557$ & $24 \cdot 40$ & $7 \cdot 653$ \\
\hline
\end{tabular}

Table III. contains the electrical constants of these rods; $r_{t}$ being the observed resistance per centimetre, at $t^{\circ}, \alpha$ the temperature coefficient, and $s_{0}$ the corresponding specific resistance at $0^{\circ} \mathrm{C}$. The wires were quenched on June 1st and 2nd, 1885, and the measurements made at the time given, only a few days after hardening. Sections and radius are 
given under $q$ and $\rho$ respectively. In most cases $q$ is individually determined.

'TABLE III.-Specific Resistance of the Glass-hard Steel Rods, measured June 4th and 8th, 1885.

(Effective length 20 centim. to 26 centim.)

\begin{tabular}{|c|c|c|c|c|c|c|}
\hline No. & $q \times 10^{8}$. & $2 \rho \times 10^{3}$. & $r^{t}$ & $t$. & $\alpha \times 10^{3}$ & $s_{0}$. \\
\hline & centim. ${ }^{2}$ & centim. & microhm. & ${ }^{\circ} \mathrm{C}$ & & microbm. \\
\hline 1 & 5152 & & 9260 & $27 \cdot 5$ & 1.5 & $46 \cdot 0$ \\
\hline 2 & 5168 & & 9250 & $27 \cdot 8$ & $1 \cdot 5$ & .46 .0 \\
\hline 3 & 5126 & & 8870 & $28 \cdot 3$ & 16 & $43 \cdot 7$ \\
\hline 4 & 5173 & & 8810 & $27 \cdot 0$ & $1 \cdot 6$ & 438 \\
\hline 5 & 5139 & & 8810 & $27 \cdot 2$ & $1 \cdot 6$ & 437 \\
\hline 6 & 5165 & $80 \cdot 6$ & 9260 & 26.8 & 1.5 & $46 \cdot 1$ \\
\hline 7 & 5164 & & 9200 & $27 \cdot 0$ & 1.5 & $45 \cdot 8$ \\
\hline 8 & 5143 & & 9260 & $26 \cdot 3$ & 1.5 & $46 \cdot 0$ \\
\hline 9 & 5174 & & 8720 & $26 \cdot 3$ & $1 \cdot 5$ & 436 \\
\hline 10 & 5214 & & 8050 & $25 \cdot 1$ & $1 \cdot 5$ & $45 \cdot 1$ \\
\hline 11 & 1520 & 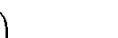 & 30670 & $25 \cdot 2$ & 1.5 & $45 \cdot 1$ \\
\hline 12 & 1520 & & 30320 & $25 \cdot 3$ & $1 \cdot 6$ & $44 \cdot 4$ \\
\hline 13 & 1520 & 44 & 30620 & $24 \cdot 8$ & 1.5 & 450 \\
\hline 14 & 1520 & & 30080 & $25 \cdot 5$ & $1 \cdot 6$ & $44 \cdot 1$ \\
\hline 15 & 1520 & & 30990 & $26 \cdot 8$ & 1.5 & $45 . \overline{4}$ \\
\hline 16 & 12560 & ) & 3400 & $26 \cdot 4$ & $1 \cdot 7$ & $41 \cdot 0$ \\
\hline 17 & 12610 & & 3382 & $26 \cdot 4$ & $1 \cdot 7$ & $41 \cdot 0$ \\
\hline 18 & 12400 & $126 \cdot 5$ & 4144 & $26 \cdot 6$ & 1.5 & $49 \cdot 5$ \\
\hline 19 & 12650 & & 3643 & 267 & 1.6 & $44 \cdot 3$ \\
\hline 20 & 12620 & & 3427 & $27 \cdot 2$ & $1 \cdot 7$ & $41 \cdot 5$ \\
\hline
\end{tabular}

Finally, Table IV. contains the electrical constants of these rods made about 37 months after the first measurement. It also contains the variations, $\Delta r_{t}$, of the resistance per centimetre, as well as the variations, $\Delta \varepsilon_{0}$, of the specific resistance. It will be seen that $\Delta s_{0}$ is negative throughout, whereas the effect of atmospheric influence and the unavoidable abrasion in cleaning the surfaces of the wires before measurement, would produce a positive error. The same bridge and the same standards of German silver are used both in the measurements of Table III. and of Table IV. The fact that the wires differ in diameter, and therefore very largely in resistance, is a guarantee against the effect of differences of sectional errors of the bridge-wire. Again, although $\Delta s_{0}$ is essentially the difference of secular change between the steel wire and the Germansilver standards, the fact that two standards $(1.0 \mathrm{obm}$ and $0.1 \mathrm{ohm}$ respectively) were used, at least partially eliminates 
the error due to variations in the standards. Moreover, the electrical effects of corresponding variations of temper (steel) and of the drawn strain which the German silver may possibly carry are enormously different. For instance, if glass-hard steel is boiled long enough the change of resistance may reach 12 per cent. and more. The effect of boiling German silver is of the order of some tenths per cent." Hence I apprehend no serious error in ascribing the whole of the observed variation of $s_{0}$ in Table IV. to secular annealing of the glasshard steel rods under experiment.

TABLE 1V.- Specific Resistance of the Glass-hard Steel Rods, measured July 9th, 1888, and the Secular Variation.

( $q$ as in Table III.; effective length about 23 centim.)

\begin{tabular}{|c|c|c|c|c|c|c|c|}
\hline No. & $2 \rho \times 10^{6}$ & $r_{t}$. & $t$. & $\Delta r_{t}$. & $a \times 10^{3}$. & $s_{0}$. & $\Delta s_{0^{*}}$ \\
\hline & contim. & mierohm. & ${ }^{\circ} \mathrm{O}$. & microhm. & & microhm & microhm. \\
\hline $\begin{array}{r}1 \\
2 \\
3 \\
4 \\
5 \\
6 \\
7 \\
8 \\
9 \\
10\end{array}$ & 806 & $\begin{array}{l}8460 \\
8430 \\
8010 \\
7950 \\
8010 \\
8460 \\
8400 \\
8510 \\
7920 \\
8170\end{array}$ & 28 & $\begin{array}{l}-790 \\
-820 \\
-860 \\
-850 \\
-830 \\
-800 \\
-800 \\
-750 \\
-800 \\
-780\end{array}$ & $1 \cdot 7$ & $\begin{array}{l}41 \cdot 7 \\
41 \cdot 7 \\
39 \cdot 3 \\
39 \cdot 3 \\
39 \cdot 4 \\
42 \cdot 0 \\
41 \cdot 5 \\
41 \cdot 9 \\
39 \cdot 2 \\
40 \cdot 8\end{array}$ & $\begin{array}{l}-4.2 \\
=4.3 \\
=4.4 \\
-4.4 \\
=4.3 \\
=4.1 \\
=4.3 \\
-4.1 \\
=4.3 \\
-4.3\end{array}$ \\
\hline $\begin{array}{l}11 \\
12 \\
13 \\
14 \\
15\end{array}$ & 44 & $\begin{array}{l}27860 \\
27710 \\
28000 \\
27490 \\
28400\end{array}$ & 29 & $\begin{array}{l}-2810 \\
-2610 \\
-2620 \\
-2590 \\
-2590\end{array}$ & $1 \cdot 7$ & $\begin{array}{l}40 \cdot 5 \\
40 \cdot 3 \\
40 \cdot 7 \\
40 \cdot 0 \\
41 \cdot 3\end{array}$ & $\begin{array}{l}-4.6 \\
-4.2 \\
-4.3 \\
-4.1 \\
-4.1\end{array}$ \\
\hline $\begin{array}{l}16 \\
17 \\
19 \\
20\end{array}$ & 126.5 & $\begin{array}{l}2807 \\
2807 \\
2830 \\
2808\end{array}$ & 29 & $\begin{array}{r}-590 \\
-570 \\
-\quad 810 \\
-\quad 620\end{array}$ & $2 \cdot 1$ & $\begin{array}{l}33 \cdot 3 \\
33 \cdot 4 \\
33 \cdot 8 \\
33 \cdot 5\end{array}$ & $\begin{array}{l}-7.7 \\
-7.5 \\
-10.5 \\
-8.0\end{array}$ \\
\hline
\end{tabular}

Summarizing the results of Tables III. and IV., it appears that during the 37 months between the two series of observations the specific resistance of the rods has fallen from 46.5 to 42.5 in case of the thin rods (diameter $<\cdot 08$ centim.), and from 43.7 to 35.4 in the case of the thicker rods (diameter -13 centim.). Hence the variations are a decrement of specific resistance amounting to some ten or even twenty per cent. in the extreme cases. This may be stated succinctly as follows :-mean atmospheric temperature acting on freshly

${ }^{*} C f$. Bulletin U. S. G. S. No. 14, p. 94. 
quenched steel for a period of years, produces a diminution of hardness about equal to that of $100^{\circ} \mathrm{C}$. acting for a period of hours. Similar results have been suspected for magnetic measurements; but such results are very much less easily interpretable than the electrical data of Table IV. For earlier measurements * prove conclusively that the electrical variations in question are sufficient evidence for the occurrence of concomitant changes of hardness, volume, carburation, \&c. Finally, the above results show that the method of tempering magnets proposed by Dr. Strouhal and myself $\dagger$ warrants the steel against secular structural instability for a time certainly exceeding three years.

Phys. Lab. U. S. G. S.,

Washington, D.C.

XLV. Evidence of the Quantivalence of Oxygen derived from the Study of the Azo-Naphthol Compounds. By RAPHAEL MELdola, F.R.S., F.C.S., F.I.C., Professor of Chemistry in the City and Guilds of London Institute, Finsbury Technical Colleget.

T $\mathrm{T}$ has long been known that by the action of diazo-salts 1 upon the naphthols and naphthylamines two parallel series of azo-derivatives are obtained which possess different characters according as they belong to the $\alpha$ - or $\beta$-series. Thus the azo-derivatives of $a$-naphthol are distinctly phenolic in character, dissolving readily in alkalies and being thrown out again by acids in accordance with the general properties of all the oxyazo-compounds. Similarly, the azo-derivatives of $\alpha$ naphthylamine have the general characters of true amidoazocompounds ; the $\mathrm{NH}_{2}$-group, which they undoubtedly contain, can be readily diazotized, and by this means a series of secondary azo-compounds can be prepared. When the azo-derivatives of the $\beta$-series are compared with the corresponding $\alpha$-compounds marked differences are found to exist. These differences between the two classes of azo-compounds are too distinct to be attributed to the isomerism of position only-there are, in addition to such physical differences as those of melting-point and crystalline form, deeper-seated chemical distinctions which have suggested a different constitution for the two classes of compounds.

* Cf. this Magazine, August.

$\dagger$ Bull. U.S.G.S., No. 14, p. 171, 1885.

$\ddagger$ Communicated by the Author, having been read at the Bath Meeting of the British Association, in connexion with the discussion on Valency. 